Georgia State University

ScholarWorks @ Georgia State University

\title{
Uncovering the Coverings: The Use of Corporate-Sponsored Textbook Covers in Furthering Uncritical Consumerism
}

Deron R. Boyles

Georgia State University, dboyles@gsu.edu

Follow this and additional works at: https://scholarworks.gsu.edu/eps_facpub

Part of the Education Commons, and the Education Policy Commons

\section{Recommended Citation}

Boyles, Deron R., "Uncovering the Coverings: The Use of Corporate-Sponsored Textbook Covers in Furthering Uncritical Consumerism" (2005). Educational Policy Studies Faculty Publications. 9. https://scholarworks.gsu.edu/eps_facpub/9

This Article is brought to you for free and open access by the Department of Educational Policy Studies at ScholarWorks @ Georgia State University. It has been accepted for inclusion in Educational Policy Studies Faculty Publications by an authorized administrator of ScholarWorks @ Georgia State University. For more information, please contact scholarworks@gsu.edu. 


\section{UNCOVERING THE COVERINGS: \\ CORPORATE-SUPPLIED TEXTBOOK COVERS}

Deron Boyles

Georgia State University

The Center for Science in the Public Interest (CSPI) recently released a report charging that corporations in the food industry are increasing their efforts to market unhealthy foods to children. ${ }^{\mathrm{i}} \quad$ Part of the concern the report raises involves the techniques used to market certain foods to students in schools. From Krispy Kreme promotions that offer students a donut for every A to “the Oreo Adventure game [called an 'advergame’] on Kraft Foods’ Nabiscoworld.com web site. . .[that has children's] 'health' ratings reset to '100 percent' when kids acquire golden cookie jars on a journey to a Temple of the Golden Oreo,” marketing is big business and health seems to be marginalized or overlooked. ${ }^{\text {ii }}$

"No amount of eye-rolling can capture how hypocritical it is for food company flacks to talk about 'moderation, balance, and exercise,” said CSPI executive director Michael F. Jacobson. "Anyone who looks at these marketing techniques can see that they encourage excess, not moderation. Almost exclusively, they encourage consumption an unbalanced diet of high-cal and low-nutrient foods. And to link junk foods like Oreos or Pepsi to physical fitness or athletic prowess has to be one of the most cynical and unfair marketing strategies I’ve ever seen.”,ii

This essay extends the critique of business influences in schools by examining one specific medium for corporate marketing-textbook covers. It is not unusual for businesses to supply schools with "free" textbook covers, to be sure. The covers are typically handed out by 
schools via teachers and are ostensibly offered at no cost. Yet the covers often feature cartoon characters, snack foods, sport drinks, athletes, celebrities, and television shows. These elements of the marketing campaign are precisely the kind of features CSPI criticized businesses for using. But is the criticism justified?

In this paper, I wish to explore the various kinds of book covers that exist to see if a meta-narrative can be discerned. I also wish to question the degree to which the various covers indicate, inscribe, or otherwise represent cultural values that might be-consistent with the CSPI report-problematic. In a basic and general sense, my intent is to investigate what symbols are actually represented on the dust jackets. What meanings do they foreclose or "cover" over? What messages might they send? This paper, therefore, highlights and describes a series of textbook covers, from over one hundred, that have been provided to me by various students, colleagues, and friends. Accordingly, this is not an exhaustive review of book covers. I am analyzing what I have been given with the intention of analyzing the symbols, meanings, and the pros and cons of using book covers in schools. Ultimately this paper questions the role teachers play in promoting, wittingly or not, commercialism in schools.

\section{Food and Nutrition: Toucan Sam and Friends}

Picture “Toucan Sam,” the cartoon mascot for "Froot Loops” cereal whose "nose” helps him “find fruity flavors” (Kelloggs/Cover Concepts, 2000). The book cover on which Toucan Sam appears has the mock title "Birds Weekly.” As with some magazines, titles of articles appear on the cover. In this case, the dust jacket philosophically asks, as one of the "subheadings," "Chicken or Egg: Which Came First?” Other “stories” purporting to appear inside “Birds Weekly” include "Building Your Nest Egg” and the added bonus of "Beak of the Month.” Above the title appears the 
question “What's the Best Birdseed?” and in larger letters, next to the cartoon figure himself, is the promise that the "magazine" has the "Inside Story of Toucan Sam" (Kelloggs/Cover Concepts, 2000; italics in orginal). The back cover of the dust jacket provides background on toucan birds, via the cartoon character. Five pictures appear, along with a graphic in the background. The caption next to the first picture proclaims: "Toucan birds love fruit. And Toucan Sam is no exception-his big nose helps him find it anywhere." The caption beside the next two pictures reads: "He goes to great lengths tracking down the most delicious fruit flavor." The final caption notes "And that fruity flavor usually ends up being Kellogg's Froot Loops cereal. This is one taste this bird can’t resist.” The graphic behind all of the pictures and captions appears to be a large, twisted tree. It has a line drawn to it with the claim that the "Background photo-[is the] home of Toucan Sam."

A cursory glance at the dust jacket might give the impression that it represents a magazine, one that has stories inside. Because it is only a book cover, however, there are no actual stories. In fact, the only "information" vaguely related to the "articles" listed on the front cover is the singular claim on the back of the dust jacket that toucan birds love fruit. What is pictured, however, is a cartoon character and mascot for a sugary cereal. Supplied to students for "free" this book cover is obviously a not-too-covert advertising campaign. Images of the cereal appear on the front cover, the registered name and iconography appear on what would be the spine of the book (next to a student's name), and the product is featured again on the back cover, equating fruit to the cereal.

What makes it somewhat unique among book covers is that it uses a magazine format (rather than the more common "games" or illustrations of sports). It even purports to provide "factual" information. That toucan birds love fruit may be true, but the narrative Kellogg's provides is one that subsumes the tid-bit of factual information within the story of the cartoon character's search for food. Forget that "fruit" is spelled "f-r-o-o-t." Forget that the fruit pictured actually has a 
collection of non-proportional illustrations of fruit. ${ }^{\text {iv }}$ Forget even that the bird is claimed to have a nose rather than a beak. The book cover represents what is so problematic about market logic masquerading as philanthropy in schools-misinformation, image as reality, and commercialism. I return to these issues and explore them in more detail at the end of this article, but other "food" examples of book covers further the point.

In addition to Kellogg's, Wyler's and Mondo have a book cover touting their soft drink mix and squeeze bottle products. The feature of the cover is the product, with two figures of young people skateboarding and rollerblading. Like other book covers, this cover promotes consumerism and specifically encourages students to take coupons home to their parents. In fact, the cover states “Hey Kids, Bring Savings Home!” (Jel Sert, 1997). ${ }^{v}$ This concept of “savings,” however, belies the fact that the only kind of savings you get is when you actually spend money. "Savings" via spending is one view of "savings," but a consumerist one void of alternatives like not buying the product in the first place and really saving on the cost of the product not purchased. "Saving” one's teeth by not consuming that much sugar is also not relayed in the concept proffered here.

The Quaker Oats Company has a chewy granola-bar-strewn cover with bits of trivia: "It would take 4,042,105 Quaker Chewy Granola Bars to fill up a soccer field!” (Kellogs/Cover Concepts, 1997). “Over 3 billion pounds of chocolate are eaten every year in the U.S.!”; “The fastest speed ever achieved on a bicycle is 152.284 miles per hour!”; “The world record for bouncing a soccer ball on one’s head is 7 hours and 16 minutes!”; “A worker bee makes only 1/12 of a teaspoon of honey in its entire lifetime!” Aside from the incessant exclamation points after each point of trivia, one wonders about the choice of the trivia. Why is chocolate featured? Why are bouncing soccer balls and bicycle speeds included? When the company claims that it takes 4,042,105 of their bars to fill up a soccer field, what do they mean? Are the bars covering the field 
at a depth of only one bar or does "fill” mean bars stacked on top of one another until they reach the upper bar of goal net structure? The tidbit about honey appears next to a picture of a pot of yellow-gold liquid that is part of the purported production line of The Quaker Oats Company, but is the honey trivia suppose to spark students’ interests in entomology or something else?

No subtlety exists when the snack company Frito-Lay encourages students to "blast off for lunch” by eating any variety of chips. They use a labyrinthine puzzle that requires students to “decode” messages (e.g., “you rule,” "no limits,” “planet lunch,” etc.). They note, “Also scattered throughout the maze are bags of Doritos. . .Ruffles. . . Lay’s. . .potato chips, Chee-Tos, and Fritos. . . .Grab 'em up for a quick snack and for their coded clues” (Frito-Lay/Cover Concepts, 1997). As Carolyn Vander Schee (forthcoming) points out, the existence of marketing of snack foods is not solely responsible for the marked increase in childhood obesity. Still, she points out, efforts like marketing via book covers exacerbate the problem. Consider now some examples that might be connected with food and nutrition, but seem to me to have different messages in addition to nutritional issues. Sports: Well, Basketball Anyway

The Powerade drink company and Gatorade drink company are extensions of the food topic, but the marketing of Powerade and Gatorade are universally sports-oriented. Gatorade provides a cover that, at a distance, appears much like a traditional cover for a notebook (one with a black and white pattern all over it). They note on their cover, however, that the dust jacket contains sports figures-symbolic characters engaged in various sport activities. Two assignments are given: “Assignment \#1-There are 126 athletes playing sports on this cover (Betcha can’t find ‘em all.) Fill in the athlete's shapes with different colored pens. No two book covers look alike! Assignment \#2-Play sports. Drink Gatorade. Cool down. Keep playing sports. Repeat 6,395,917 times” 
(Gatorade/Cover Concepts, 1998).

Another Gatorade book cover features the professional basketball player Michael Jordon. The cover features Jordon's head and what appears to be an x-ray of the basketball star's body. His "drive gear" is a hamster, his heart is a basketball, and his fuel is, of course, Gatorade. The book cover also features ranked characteristics like "confidence," “focus," “motivation,” and the like. The number one characteristic is “energy.” Gatorade’s website is listed, too, along with graphics that appear to reflect an interest in human anatomy and physiology-save the basketball heart and hamster stomach. Clearly an advertisement, this book cover reflects the message that sports are important and that drinking Gatorade is what a successful athlete drinks.

Perhaps one of the most interesting book covers advertising sport drinks is the Gatorade cover featuring a battle between basketball star Vince Carter and a dinosaur. Illustrated to mimic a movie titled "Raptor vs. Raptor," (i.e., a dinosaur versus a basketball player on the team called the Raptors) the book cover has an image of a ferocious looking, blood spattered animal on one side and a cartoon version of an overly-muscled, sweat spattered basketball player on the other side. For each "star” or "character” there are specifics listed such as date of birth (January 26, 1977 for Carter; around 6 million years ago for "Ike” the dinosaur), interests (playing the saxophone for Carter; playing basketball for the dinosaur), and drinks (new Gatorade fierce grape for Carter; new Gatorade fierce berry for the dinosaur) (Gatorade/Cover Concepts, 1999-2000). According to the cover, Carter's choice of drink is “the perfect way to replenish lost fluids while kicking velociraptor butt” (Gatorade/Cover Concepts, 1999-2000). Clearly, the company is advertising its product. Equally clearly, however, is the competitive theme conveyed in the book cover. "Fierce," "kicking butt," “vs.," are key terms used alongside a clearly confrontational image of a bloody dinosaur attacking a sweaty basketball player. What messages, besides drinking Gatorade, are being sent? To what 
degree are competition, ferocity, and winning constitutive features of market logics and capitalist expectations? Are "battles” represented as “normal” or “expected” elements of reality?

Powerade’s book cover features the message that it’s "Powerflo" drink is fast and that, by extension, if you drink it, you too will be fast. In all, speed and going faster than others is a valuable goal. Hockey, track, soccer, basketball, and baseball are among the primary images featured on the cover. Words in large print reinforce the message. "The new Powerflo is fast. It's faster than your mother, your father, your dog, your cat, you car, boat, bike, or best friend. ...” (Powerade/Cover Concepts, 1997). Of the fifteen images of people featured in the ad, six have their backs to the camera or are in silhouette (a little league baseball player, two firefighters, a race car driver, and two hockey players). Everyone else is unmistakably male and the imagery suggests that the other figures are also male. Might this book cover indicate that competition is central? Might the cover also suggest that males are the ones to compete, since females are, with near certainty, not even represented on the cover at all?

The gender issue raised in the Powerade cover pales in comparison to a book cover from Champs Sports (Champs Sports/Cover Concepts, 1997). On this book cover, more basketball players are featured-on one side as bobble-head-like figurines and on the other as actual images of people engaged in some aspect of playing basketball. Professional basketball jerseys are pictured on the edges of the cover and the "Champion" label is identified as "the only guys who make NBA replica jerseys” (Champs Sports/Cover Concepts, 1997; italics added). Most interesting and arguably most troubling, however, are the four groupings of people featured on the cover itself. In each of the four groups, there are four people photographed separately and then added together to show what appears to be a younger child, an older child, a teenager or young adult, and then a professional basketball player. Each of the positions or movements featured (i.e., two groups about 
to shoot the ball, the other two groups dribbling), start at what appears to be the beginning or basic step (featuring the images of the youngest players) and then gradually advances through the motion of shooting the ball or dribbling (featuring the images of professional basketball players).

Forget for moment that of the sixteen people pictured, two appear to be Euro-American or Anglo males, five appear to be African-American or Mixed Race females, and nine appear to be African-American or Mixed Race males. ${ }^{\text {vi }}$ The numbers of representation become less important when one looks closely at the two groups featuring women. Of the two, both begin with two young women. In one of the groups, however, the third woman featured actually has one female arm and one male arm-each of a different color but the male arm featured on the female matches the color and shape of the male pictured at the end of the process. Quite simply, the women pictured in the two groupings morph into men. Given the stage-like or developmental nature of the illustration, it appears that the women represent only the beginning stage while the men illustrate the pinnacle or fully developed form. What message does the Champion brand of clothing wish to send? What do students take away from seeing such imagery? What values, if any, are being suggested by having women transform into men? Why, for example, are professional basketball players who happen to be women not featured as the pinnacle? It is difficult to know what messages are actually received or understood (if any). Yet, why are the sports and sports drink book covers primarily in deep hues of blues and greens-with plenty of black as a primary color-while the book covers obviously marketed to girls are primarily pink, purple, and pastel blue?

“Secret Paths,” Not so Secret Gender Identity Construction

Of the book covers I received, three clearly seem directed at girls. The first of these covers advertises "Purple Moon,” a girls-only website that apparently provides a place for girls to "collect treasures. . .play cool activities and meet other girls!” (Purple Moon/Cover Concepts, 1997). The 
cover features butterflies, angels, hummingbirds, flowers, and “secret stone” jewels. The cover also includes an advertisement from a clothing store ("Fun Times and Fun Clothes...Wear the Coolest from Jonathan Martin Girls. . .at a mall near you”), and a lip gloss company (“Win fruitlicious lip gloss from LipSmacker. . . . The original fun flavored lip gloss that’s good for your lips”).

Unfamiliar with Purple Moon, I heeded their advice to visit their website (purple-moon.com). When I did, however, I found a page noting that the site was under construction. "In the meantime," the message on the website read, "visit one of our sister sites: Barbie.com, DivaStarz, and GenerationGirl.com.”vii

The other two covers directed at girls are Mary-Kate and Ashley covers, advertising their videos and fan-club website. Puzzles appear on the covers, including the maze "Can you find your way through the mall?” and the letter scramble "Search for 7 costume party words hidden in the square below." Each of the puzzles corresponds to videos by the actresses ("Mall Party” and “Costume Party,” for example), but the messages seem to be that if you are a girl, you should shop, dress up, and "party.” Whether there is a cause-effect relationship between young women viewing a book cover and shopping at the mall is not the point. My claim is not that viewing $x$ means $y$ will happen. My point is that the construction of identities is already so pervasive in general society that for corporations to use book covers as sales tools in schools seems to me to be overkill and a particularly specious form of exploitation. Corporations also manipulate societal norms and sell them back to girls; in essence the girls get the norms "for free” when they participate in societal institutions, but the norms make it incumbent upon girls to consume (and such consumption is not “free”). Indeed, the larger claim here is that sexism is a commodity and an ideology deeply rooted in and deeply valued by corporate interests.

Beyond the Mary-Kay and Ashley videos, other book covers tout the line-up for morning 
cartoons on the Cartoon Channel. Pokemon book covers advertise various movies. The Fox Family Channel plugs four shows in their morning line-up and four in their afternoon lineup. One group starts at 7 am and the other at 3 pm, which happens to coincide with the times just before and just after many elementary schools start and finish the day. PlayStation has a book cover, as well. It urges the viewer to “Give History a Wedgie” by playing their various action-adventure games.

To be as judicious as I can, there are book covers that might be perceived by some to be more valid or defensible than what has been described above. In the pile of book covers I received, three urged students not to smoke and one featured endangered species and geography games for identifying where endangered animals reside. The problem, of course, is that the no-smoking campaign is underwritten by the Phillip Morris company due to a court order and the endangered species book cover carries with it advertisements for Johnson \& Johnson soap products (albeit with dispensers of the soap carrying pictures of animals).

\section{Misinformation, Image as Reality, and Commercialism in Schools}

The book cover has become the mini-billboard students carry around with them. Of course not all students use the book covers and not all students pay attention to the graphics, symbolism, and meanings behind the messages they see. But when schools hand out book covers, one wonders whether students receive the message that the covers are sanctioned by the school and hence have some form of validity or acceptance. When teachers pass book covers out to students do the teachers' actions imply that they sanction the messages, symbols, and meanings embedded (or embossed) in the book covers? What responsibility, if any, do teachers have in such a process? What opportunity do the book covers represent to develop or further develop critical thinking and 
critical consumerism on the part of students?

Some may protest that the analysis of book covers provided here is over-blown. On this view, too much attention is being paid to a form of hyper-analysis and we should simply relax. Students are already bombarded with commercial images and messages in their lives, so book covers are only an extension of the world in which they live. I believe many parents and many teachers would articulate such a view, either out of a defensive sense that they are being blamed for everything as it is (and this issue is another straw on the camel's back) or out of a general malaise which uncritical consumerism yields.

After pointing out such a possible objection to this overall inquiry, I want to pre-empt the point by maintaining that teachers and schools have different obligations to their students than to advance a private, corporate, commercial series of interests. I am not arguing that schools do not already advance such interests, but that they should not. Said more directly, I am asserting that schools should not be places where teachers allow the uncritical acceptance of any narrative, much less the clearly lopsided narrative put forward by corporate advertising campaigns qua book covers. By not investigating with students (and others?) the possible symbols and cultural messages that are featured in book covers like the ones detailed in this paper, two points seem clear: 1) teachers may be committing a form of educational malpractice or intellectual negligence; and 2) teachers may be hegemonically reinforcing the very stereotypes and power structures that cause them to struggle in their daily lives as teachers. Ironically, what may at first appear to be a set of teacher-bashing claims is actually intended to advance a form of teacher power that comes from raising questions. ${ }^{\text {vii }}$

At what point should individuals consider it appropriate to question the corporate influence over public schooling? When should teachers ask questions of principals, school boards, and politicians about corporate influence? The idea of using critical analyses of book covers as one 
aspect of an on-going and never-ending process aimed toward developing critical transitivity and democratic responsibility does not seem to me to permeate current U.S. society nor the sub-society of teachers in U.S. schools. Instead, schools are seen by businesses, business advocates, and consumer materialists as the place for children to "get” an education in order to "get” a job. Further, businesses use schools as captive markets where they can test new merchandise, advance their public relations, and appear philanthropic by “donating” materials to schools. This is part of the problem with the book covers. They are "free," so they are either eagerly sought after or merely accepted since the hegemonic message so deeply reinforced in the U.S. is that schools are now and forever will be under-funded, so anything free must be accepted (and because it is accepted is good?). Teachers are often grateful: even for book covers.

I cannot help but wonder about the perversity of championing book covers as helping, in an economic sense, extend the life of textbooks that, on their own, are arguably corporate vehicles for reinforcing particular values, histories, and ideologies over others-but in covert ways. On this view, we have corporate covers covering corporate curriculum. Aside from this point, however, we are faced with students accepting donated goods (tax deductible for businesses) and for what educational value? I am not denying the possibility that students may question the covers on their own, reject them out of hand, or use them in subversive ways. I am claiming, however, that they are put in positions where reality is presented to them and if unchallenged, sets in motion (or a form of non-motion) a pattern of non- or even anti-criticality.

It is as though teachers are acting as surrogate telemarketers. Imposing the corporate covers on students without reflection or critique of their roles, it is taken as a given part of many (though not all) teachers’ jobs. Unlike telemarketing, however, students have no mechanism to opt out of being “called" in the first place. There is no "no call list" for them to save themselves from teachers 
passing out covers-even if they do not wish to accept one. They are still at the place where they have to answer the "call," even if they reject the "call” to take and use the cover and even if they reject the "calls" the covers represent. In terms of book covers, I believe teachers too often ask students to raise their hands if they want one, not engage students in analyzing and critiquing them.

Let me try to make clear that a call for analysis and critique in schooling, multiple ways of knowing, and critical transitivity should not be associated, to any degree of seriousness, with superfluous references to student choice in current classrooms. In current classrooms, students many times “choose” between booklets from Time, Inc., or the advertisement-riddled Channel One programming station. They also get to choose whether they want the Gatorade book cover featuring Michael Jordon or the Secret Path book cover featuring Barbi, lipstick, and clothing. But is this choice? If so, what kind of choice is it? To paraphrase Kozol, current schooling may answer the charge of promoting anti-intellectual and anti-democratic values by pointing to the aforementioned “choices,” as well as to their learning centers, baby rabbits, and three-thousand-dollar vouchers. This is offered as evidence of freedom. But is it, really? Kozol (1975/1986) writes:

They have the right to choose without constraint among a thousand paths of impotence, but none of power, the right to demonstrate their sense of ethical surrender in ten different innovative "resource areas” and at twelve separate levels of proficiency. Like first class passengers on board a jet flight to a distant city, they have their choice of any drink or food or magazine or padded seat they prefer; but they are all going to the same place, they are all going there at the same rate of speed, and the place that they are going is a place neither they, nor you, nor I, but someone else they do not know has chosen for them. They have no 
choice about the final destination. They have no choice about the flight, the price, the pilot or the plane; but they can stretch their legs, and walk along the aisle, and select their magazine, and they can call this freedom.

My desire is to fashion a view of teaching and learning that legitimates schools as contested, public spheres and teachers as critically transitive agents who work toward forms of social justice, multiple forms of knowing, and critical considerations of the merits and demerits of capitalism and the corporate state. The need is to broaden the definition of teachers, authority, and ethics to include and legitimate educational practices linking democracy, intellectualism, teaching, and practical learning. It means, in part, that book covers should be used as object-lessons: a "free” and available tool to engage students in revealing, reworking, questioning, and possibly even re-appropriating the symbols and cultural values they are confronted with daily. Giroux (1988) contends the substantive nature of this task takes as its starting point the ethical intent of initiating students into a discourse and pedagogical process that advances the role of contestation within the school while addressing market logic masquerading as philanthropy in schools, misinformation, image as reality, and the commercialism that structures the daily lives of people in the United States and the world. $^{\text {ix }}$

Extending Giroux, Pierre Bourdieu (2003) calls for bringing together "specific individuals" (a la Foucault) in a collective form (“collective intellectual” for Bourdieu) to confront the production of pro-market, pro-careerist, pro-globalization narratives. “This collective intellectual,” he writes, “can and must, in the first place, fulfill negative functions: it must work to produce and disseminate 
instruments of defense against symbolic domination that relies increasingly on the authority of science (real or faked)” (20). If the intellectual is "buttressed by the specific competency and authority of the collective thus formed, it can submit dominant discourse to a merciless logical critique aimed not only at its lexicon (“globalization," “flexibility,” “employability,” etc.) but also at its mode of reasoning in particular at the use of metaphors (e.g., the anthropomorphization of the market)” (20). Teachers and students as collective intellectuals, accordingly, should be able to take the discourse represented in items like book covers and "subject this discourse to a sociological critique aimed at uncovering the social determinants that bear on the producers of dominant discourse. . .and on their products” (20). We would do well, then, to focus teacher and student energy on deconstructing and reconstructing the economic, corporate, and capitalist assumptions surrounding and infiltrating schools. The values that are transmitted, or at least symbolically represented, are too pervasive to let that very pervasiveness be an excuse not to grapple with and engage things like newspaper advertisements, magazines, websites, television news programs-and, yes, textbook covers. 


\section{REFERENCES}

Bourdieu, P. 2003. Firing Back: Against the Tyranny of the Market 2. Loïc Wacquant trans. New York: The New Press.

Champs Sports book cover (Braintree, MA: Cover Concepts, 1997), cover \# 99779.

Coca-Cola Company, Powerade book cover (Braintree, MA: Cover Concepts, 1997).

Frito-Lay, Inc., “Blast Off for Planet Lunch” book cover (Braintree, MA: Cover Concepts, 1997), cover \# 99739.

Gatorade book cover (Braintree, MA: Cover Concepts, 1998).

Gatorade book cover (no attribution, in author’s possession).

Gatorade book cover (New York: Cover Concepts, 1999-2000), Spring 2000 cover \# 99491.

Giroux, H.A. 1988. Schooling and the Struggle for American Life. Minneapolis: University of Minnesota Press.

Jel Sert Company, “Taste the Difference” and “It’s Your World!” book cover (West Chicago, IL: The Jel Sert Company, 1997).

Kellogg Company, “Birds Weekly” book cover (New York: Cover Concepts, 2000), cover \# 99483.

Kozol, J. 1975/1986. The Night is Dark and I Am Far From Home: A Political Indictment of the U.S. Public Schools. New York. The Continuum Publishing Corporation.

Purple Moon Media, Purple Moon book cover (Braintree, MA: Cover Concepts, 1997), cover \# 99789.

Quaker Oats Company, Chewy Granola Bars book cover (Braintree, MA: Cover Concepts, 1997).

Vander Schee, C. forthcoming. “The Privatization of Food Services in Schools: Undermining Children's Health, Social Equity, and Democratic Education.” in Schools or Markets?: Commercialism, Privatization, and School-Business Partnerships. Mahwah, NJ: Lawrence Erlbaum Publishers. 


\section{NOTES}

i.See http://www.Cspinet.org $>$ Accessed 18 November 2003.

ii.Ibid.

iii.Ibid.

iv.Of the lime, orange, and cherry pictured, the cherry is more than half the size of the lime.

v.In what may be an odd theme among fruit represented on book covers, the Wyler's portion of the book cover has four pieces of fruit pictured (kiwi, cherry, pineapple, and strawberry), with the cherry equal in size to the slice of kiwi.

vi.Clearly, there are also racial messages within the representation that reinforces assumptions about African Americans, basketball, and sports.

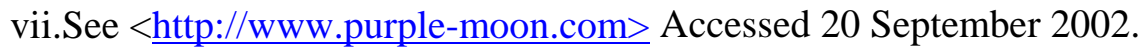

viii.I also wish to point out that while I am focusing on teachers, students are also a prime concern. Indeed, students are at times the barrier to corporate messages. Those messages and their entailing meanings, after all, require interpretation on the part of the receiver. Students may parody the symbols, reject the book covers out of hand, or give so little attention to their meaning that no effect takes hold.

ix.See Henry Giroux, Schooling and the Struggle for American Life (Minneapolis: University of Minnesota Press, 1988). 